GLOBAL MEDICAL ETHICS

\title{
Ethical issues in funding orphan drug research and development
}

\author{
C A Gericke, A Riesberg, R Busse
}

J Med Ethics 2005;31:164-168. doi: 10.1136/jme.2003.007138

This essay outlines the moral dilemma of funding orphan drug research and development. To date, ethical aspects of priority setting for research funding have not been an issue of discussion in the bioethics debate. Conflicting moral obligations of beneficence and distributive justice appear to demand very different levels of funding for orphan drug research. The two types of orphan disease, rare diseases and tropical diseases, however, present very different ethical challenges to questions about allocation of research funds. The dilemma is analysed considering utilitarian and rights based theories of justice and moral obligations of non-abandonment and a professional obligation to advance medical science. The limitations of standard economic evaluation tools and other priority setting tools used to inform health policy decision makers on research funding decisions are outlined.

See end of article for authors' affiliations

Correspondence to:

Correspondence to:
Dr C Gericke, Department of Health Care

Management, Technische Universität Berlin, Strasse des 17. Juni 145, D10623 Berlin; christian. gericke@tu-berlin.de

Received7November 2003 In revised form

23 December 2003

Accepted for publication

11 January 2004
1

nternational research ethics has been primarily concerned with protecting individual participants from possible harm during the process of research. A recent guideline has also stressed the importance of considering access to outcomes of research in participating communities in low resource settings. ${ }^{1}$ However, the level, allocation, and priority setting of resources for funding development of new treatments have not featured significantly in bioethics debates. Multidisciplinary discourse on the level of healthcare resources and their fair distribution has long focused on existing treatments. In recent years, international organisations have expressed concern about the lack of research into new treatments for health problems that are most prominent in poor countries..$^{2-4}$

Orphan drugs have been defined as drugs unlikely to be manufactured by private industry unless special incentives are provided by others. ${ }^{56}$ The two main reasons why industry may be reluctant to invest in research on orphan drugs are:

- the condition is too rare to represent a profitable market, and/or

- the condition is prevalent in developing countries which are too poor to pay drug prices that render the new drug profitable for the patent holding manufacturer.

The latter are often called "neglected diseases" or-as in this article- "tropical diseases" to distinguish them from the former, the so-called rare diseases. ${ }^{6}$

A number of industrialised countries have passed specific legislation defining epidemiological or/and economic criteria for designation of orphan status and consequent incentives to counteract the neglect of orphan diseases in industrial research. After the launch of the US Orphan Drug Act in 1983, Japan (1993), Taiwan and Australia (1997), and lately the European Union (EU) (2000) have passed laws to incite the pharmaceutical and biotechnological industries to pursue research on orphan drugs by providing tax breaks and market exclusivity. ${ }^{6}$ In the EU, a drug will receive orphan status designation if it is intended for the diagnosis, prevention, or treatment of a life threatening or chronically debilitating condition which affects not more than five people per 10000 in the Community (Regulation (EC) No 141/2000). This epidemiological threshold can be extended to more frequently occurring diseases if they are life threatening, seriously debilitating or serious and chronic at the same time, and "if the return on the marketing of a medicinal product would not be expected to justify the investment in its development" ${ }^{8}$ In both cases, orphan drug designation may be obtained only if no satisfactory method of diagnosis, prevention, or treatment exists or if the new treatment will be of significant benefit to those affected (Article $3(1) b) .{ }^{8}$ In addition, some member states grant tax credits for clinical studies or on corporate taxes. ${ }^{6}$ The marketing exclusivity is revoked if the manufacturer is unable to supply sufficient amounts of the drug or a second applicant can show that their product is "clinically superior", which means more efficacious, safer, or otherwise of significant advantage to diagnosis or care. ' Until recently, advocacy groups as well as private industry had doubts whether tropical diseases that are prevalent in developing countries were covered by the US or EU orphan drug legislations.. The European Commission has recently clarified that drugs targeting tropical diseases are eligible for designation if they have a low prevalence in the European Community and meet all other criteria of the regulation. ${ }^{10}$

The decision of how much a society should spend on research on orphan diseases represents a moral dilemma. On the one hand, each orphan disease only represents a small number of individuals within the legal and political remits of a particular society. Investing substantial amounts of resources for rare conditions could be considered unethical from a utilitarian point of view, as it is not maximising society's benefits, 
and its opportunity cost in terms of benefits foregone for others are important. On the other hand, many would uphold that society has a moral obligation not to abandon individuals who have had the bad luck to be affected by a serious but rare condition for which no treatment exists. Furthermore, medicine has a professional obligation to advance scientific knowledge in pursuing new therapies. These conflicting moral obligations appear to demand very different levels of funding for orphan drug research and development.

In the following discussion, we analyse this moral dilemma according to the four principle approach of biomedical ethics developed by Beauchamp and Childress. ${ }^{11}$ Their framework provides an accessible and culturally neutral approach to thinking about ethical issues in health care, ${ }^{12}$ which can be applied to developed and developing countries alike. This approach comprises the four prima facie principles of respect for autonomy, non-maleficence, beneficence, and justice. For this particular dilemma, the principles of beneficence and justice are of particular relevance. The analysis of justice will cover a utilitarian and a rights based approach. The discussion of obligations of beneficence will cover the moral obligation of non-abandonment and the professional obligation of medicine to promote scientific advancement. In the last section, the main conclusions of the analysis are presented.

\section{CONFLICTING PRINCIPLES \\ Justice}

Philosophical accounts interpret justice as fair, equitable, and appropriate treatment in the light of what is due or owed to individuals. ${ }^{13}$ Various, often conflicting, theories of justice have been proposed. Here, we discuss a utilitarian and a rights based approach to the dilemma of orphan drug research funding.

\section{Utilitarian approach}

Utilitarians argue that the standard of justice depends on the sole principle of utility, which demands that we seek to maximise the overall good, ${ }^{13}$ or in other terms "to bring the greatest good to the greatest number" ${ }^{14}$ Utilitarian thinking forms the basis of economic evaluation, which is increasingly used to inform priority setting decisions in health policy. However, utilitarians disagree on which values should be maximised. ${ }^{15}$ The commonest approaches are based on maximising health benefits in terms of a single index combining life expectancy and health related quality of life, such as quality adjusted life years or disability adjusted life years. ${ }^{14}$

Maximising principles require that health care be distributed so as to achieve maximum benefit. Need principles require distribution of resources in proportion to need. Egalitarian principles require resources to be distributed so as to reduce inequality. ${ }^{16}$ Need is usually understood as capacity to benefit from treatment or in terms of severity of disease. ${ }^{14}$ This definition of need is difficult to apply to orphan diseases, as capacity to benefit is usually understood to be limited to existing treatments in order to become operational.

According to the second definition individuals with orphan diseases have a need, but since their condition is infrequent, no or very few resources would be allocated to their particular disease for the goal of maximising society's utility. However, all individuals with orphan diseases taken together represent a substantial number of people. In the EU, an estimated 25-30 million people are affected by one of around 6000 orphan diseases. ${ }^{6}$ Two separate questions arise:
- What level of resources should be devoted to orphan disease research overall?

- What level of resources should be allocated to each individual disease?

Another problem with resource allocation for research purposes is the extreme uncertainty of benefits. In economic evaluation, uncertainty of costs and benefits can be taken into account in a sensitivity analysis. But the future success of research for a particular orphan drug is too uncertain to allow meaningful estimates. This is demonstrated by the fact that on average only one in 10 pharmaceutical compounds developed is successfully marketed, which means that predictions of future benefits were misguided in $90 \%$ of cases although substantial amounts of resources are invested for research and development for each new chemical entity. Cost estimates for developing a new drug vary widely. Using confidential industry data of multinational pharmaceutical companies, DiMasi et al estimated the cost of developing a new drug at US\$231 million in 1991. ${ }^{17}$ Subsequent authors who used the same data but changed some assumptions estimated the cost of developing a new drug at US $\$ 473$ million in $2000 .^{3}$ More recent, independent estimates for cash outlays including smaller pharmaceutical companies and excluding opportunity costs for developing a new drug are in the order of US\$76-115 million including the cost of failure. ${ }^{18}$ This corresponds to estimates for the minimum size of a potential market of US\$100 million for an orphan drug to attract industrial interest. ${ }^{7}$

The tropical diseases definition also encompasses high prevalence diseases that do not represent profitable markets for industry. Today, only $10 \%$ of global health research funding is allocated to $90 \%$ of the world's health problems. ${ }^{19}$ But does a moral obligation to distribute resources fairly extend to individuals outside the economic, legal, and political remit of the society providing the research funds? Applying traditional economic evaluation to such problems is likely to fail, as maximising global health with national funds of single countries would not be politically acceptable in any country. However, international funding agencies could maintain such aims. Another problem in defining the boundaries of a moral obligation for distributive justice is the fact that even when a disease is frequent in a particular country, its importance in global or regional priority setting may be dwarfed by conditions that are more frequent in the sum of countries considered. The technical and political feasibility of a health intervention has also to be taken into account in priority setting. Intervention complexity in terms of the nature and availability of non-financial resources required to implement and sustain an intervention should thus be considered alongside priority setting techniques based on utilitarian thinking such as burden of disease assessment and economic evaluation. ${ }^{20}$

\section{Rights based approach}

Rights are justified claims that individuals and groups can make upon other individuals or upon society, and to have a right means to be in a position to determine, by one's choices, what others should do or need not do. ${ }^{15}$ An important aspect of rights based theory for health policy considerations is the distinction between positive and negative rights. A positive right requires others to do something beneficial or enabling for right bearers, whereas a negative right requires others to refrain from doing something, usually harmful or restrictive, to right bearers. ${ }^{21}$

One form of positive right that has been proposed with regard to resource allocation decisions is the right to a decent minimum of health care. In most industrialised democracies, institutions exist that assure everyone access to needed 
services regardless of ability to pay. ${ }^{21}$ This could be interpreted as a legal right to health care. ${ }^{21}$ In some countries, such as Italy and the Netherlands, the right to health care is protected constitutionally. ${ }^{22}$ The French and German constitutions contain a legal obligation to assist individuals in danger, which could potentially apply to the development of treatments for life threatening orphan diseases. ${ }^{7}$ The EU Charter of Fundamental Rights (section 35, 2000/C 364/01), which the $25 \mathrm{EU}$ member states acknowledged as part of the Constitution for Europe in June 2004, states that "Everyone has the right of access to preventive health care and the right to benefit from medical treatment under the conditions established by national laws and practices". The main problem of a rights based approach to decisions about resource allocation is that even when a right to health care is embodied in national legislation its scope is open to interpretation. The other limitation is that legal rights can only apply to the provision of existing treatment options, but it is difficult to imagine an enforceable individual right to research funding for non-existing treatments. A right to health care for individuals affected by orphan diseases can thus only be a social right or a general moral obligation. However, if one agrees on a societal moral obligation of solidarity it is questionable why the important decisions on priority setting for orphan drug research and development are left to the pharmaceutical industry, ${ }^{7}$ which public bodies only approve a posteriori to decide whether industrial proposals justify public sponsorship or not. Public-private partnerships (PPPs) can be one way to improve the current situation, and at least the African onchocerciasis PPP has been very successful in channelling industry funds into a hitherto underresearched tropical parasitosis. ${ }^{23}$ In a recent survey by Médecins Sans Frontières and Harvard School of Public Health, six of 11 multinational pharmaceutical companies reported participation in PPPs for tropical diseases, with individual financial commitments ranging from US\$500 000 to US\$4 million. ${ }^{3}$

\section{Beneficence}

Beauchamp and Childress understand beneficence broadly, including "all forms of action intended to benefit other persons" or "to contribute to their welfare". ${ }^{24}$ Beneficence requires that agents take positive steps to help others, not merely refrain from harmful acts, or to treat individuals autonomously. The principle of beneficence refers to a moral obligation to further their important and legitimate interests. Beauchamp and Childress distinguish two major principles of beneficence: positive beneficence and utility. ${ }^{24}$ The former requires agents to provide benefits, and the latter requires that agents balance benefits, risks, and costs. ${ }^{24}$

The utilitarian understanding of the principle of beneficence has been outlined above with regard to funding decisions for orphan drug research. To discuss the notion of positive beneficence in this context, we now consider the moral obligation of non-abandonment and medicine's role in advancing scientific knowledge as a professional and societal moral obligation.

\section{Non-abandonment}

Landman and Henley proposed a basic moral and public policy commitment to non-abandonment of individuals with needs for highly specialised health care when making policies for rationing and resource reallocation, even in resource constrained settings. ${ }^{25}$ The concept of non-abandonment may also be useful to reasoning about orphan diseases which received their designation because they are considered to be abandoned by free market incentive systems for drug research and development.

The laws and regulations passed in recent years to provide incentives for orphan drug research could be interpreted as attempts of democratic society to pursue the principle of nonabandonment and to counteract distributive injustice caused by market incentives. The subsidies, tax breaks, and other fiscal benefits offered to industry as incentives have opportunity costs, and resource allocation on the principle of nonabandonment may not maximise society's utility according to standard utilitarian and economic theory. However, some authors recognise the existence of "caring externalities", ${ }^{26}$ where individuals derive utility from the satisfaction of providing help to those in need. Thus, pursuing actions based on beneficence does not necessarily conflict with utilitarian reasoning.

\section{Scientific advancement}

Rhodes has argued that medicine as a profession has a generally accepted duty to advance scientific knowledge in pursuing new therapies, and this justifies some overriding of short term utility considerations.$^{27}$ Indeed, many professional medical bodies, such as the Royal College of Physicians of London have among their declared purposes promotion of advance of medical knowledge. ${ }^{28}$ Leading organisations in international health argue for increased funding for research on tropical diseases. They apply the standard priority setting tools used to inform decisions on allocation of scarce health care resources to the allocation of research funds. ${ }^{19}$ The Ad hoc Committee on Health Research proposed a five step process starting with measurement of burden of disease, followed by risk factor analysis, assessment of the knowledge base, cost effectiveness analysis, and calculation of the present level of investment into research for the condition/ risk factor under question. ${ }^{29}$ This process might be applicable to public research funding of prevalent tropical diseases but any rare disease will again be neglected.

Many rare diseases, however, merit scientific study for reasons other than prevalence or because of moral obligations of distributive justice or non-abandonment. William Harvey recognised this in 1657, when he wrote to a Dutch physician that "Nature is nowhere accustomed more openly to display her secret mysteries than in cases where she shows traces of her workings apart from the beaten path; nor is there any better way to advance the proper practice of medicine than to give our minds to the discovery of the usual law of Nature by careful investigation of cases of rarer forms of disease." ${ }^{\prime \prime 3}$ Now venture capitalists have rediscovered that the study of rare diseases often repays research efforts manifold with medical insights and useful drugs for common conditions. ${ }^{31-33}$ The main reason for this is the fact that many rare diseases result from single gene alterations producing a single defective protein, enabling scientists to see the consequences of the defect with clarity close to that of a controlled laboratory experiment. ${ }^{31}$ A good example is the study of homozygous familial hypercholesterolaemia, which led to the development of statins. ${ }^{31}$ Prior to orphan drug legislation little research was done on orphan diseases. However, the number of new compounds marketed for use in orphan diseases has increased substantially in all countries following orphan drug legislation. ${ }^{6}$ In the USA, 1261 drugs have received orphan status designation since $1983^{34}$ compared with 10 drugs which received orphan status in the decade before $1983 . .^{31}$ In the EU, 140 drugs were granted orphan status between April 2000 and May 2003..$^{35}$ Of a total of 1395 new drugs approved between 1975 and 1999 in the EU, only 13 drugs (1\%) were specifically indicated for a tropical disease. $^{3}$

Funding medical science in general has been considered as fulfilling a moral obligation of beneficence for existing patients who are given hope that treatments might be developed to cure them, ${ }^{7}$ and as a societal commitment to provide potential benefits for future generations. 


\section{CONCLUSIONS}

To date, ethical aspects of priority setting for research funding have not been a major issue of discussion in the academic bioethics debate. Research ethics is primarily concerned with protecting participants in clinical research and conflicts of interest of clinical researchers funded by industry, whereas the debate on fair distribution of resources in health care is limited to existing treatments.

Both types of orphan disease-that is, rare diseases and tropical diseases-present different ethical challenges to questions of allocating research funds. For both types the conflict between principles of distributive justice based on utilitarian or legal rights and principles of beneficence based on social or moral obligations is at the forefront. However, a more detailed analysis reveals that very different moral issues are at stake in each case. Utilitarian theory, and with it priority setting tools based on economic evaluation, fail rare disorders whereas frequently occurring tropical diseases fit into the utilitarian framework. However, the latter present the difficulty of where to draw the boundaries of moral obligations of beneficence or distributive justice. Should these be determined by national boundaries, political constituencies, or economic influence or industrial profitability? Standard tools used for priority setting in health care are considered inadequate for allocating research funds because of the extreme uncertainty of future benefits on investment. For rare diseases future benefits are particularly difficult to predict because of their, on average, increased potential for scientific breakthroughs but otherwise very limited markets and low profitability. Investing in research into rare diseases offers hope to those in need and potential benefits for future generations. These benefits, however, are difficult to quantify and incorporate into quantitative priority setting tools.

Both principles of justice and beneficence support a stronger role for the public sector in deciding on priority setting for orphan drug research funding. A public policy that prioritises, decides on choices, defines methodologies, and provides public funding for orphan drug research and development has already been proposed on ethical grounds by Pabst. ${ }^{7}$

Transparent public processes of decision making with participation of relevant civil society organisation, for example patient interest groups, would at least guarantee procedural justice, even if social justice for people affected by orphan diseases still remains a somewhat elusive and theoretical aim rather than an easily applicable concept for priority setting. ${ }^{8}$

Daniels and Sabin have proposed a process for priority setting they have called "accountability for reasonableness". ${ }^{36}$ Their framework requires that a fair priority setting process meets four conditions. Firstly, the rationale for decisions must be publicly accessible. Secondly, decisions about meeting healthcare needs must be contextually relevant to fair minded people. Thirdly, allowance must be made for appeals so that previous decisions can be reconsidered in the light of new evidence or arguments. Fourthly, there must be a process of enforcement that facilitates the implementation of the last three conditions. ${ }^{36}$

Public debate and participative and transparent procedures are as important for decisions on research funding for rare diseases in industrialised countries as they are for the allocation of funds for global health research. But this can only be a first step to address, what Benatar and Singer ${ }^{37}$ have called one of the greatest ethical challenges in today's world-the unconscionable inequities in global health. Improvement of existing tools for priority setting in global health research are urgently needed in the light of recent proposals to substantially increase funding for international health research. ${ }^{2}$
To date, pharmaceutical regulation has mainly provided incentives for research and marketing of drugs for rare diseases, and a number of national, bilateral, and international agencies fund research into neglected diseases in poor countries. ${ }^{38}$ Others like the Global Forum on Health Research seek to help correct the 10/90 gap in health research and focus research efforts on the health problems of the poor by bringing together key actors and creating a movement for analysis and debate on health research priorities, the allocation of resources, public-private partnerships and access for all people to the outcomes of health research. ${ }^{39}$ The creation of new, independent bodies at the international level offers important opportunities to stimulate research in hitherto neglected fields of health needs and to increase the transparency of resource flows for research and health care. ${ }^{24}$ However, these organisations do not have the political legitimacy in the sense elected national governments do. Yet some, like the Global Fund to Fight AIDS, Tuberculosis and Malaria, already control and allocate substantial funds for healthcare evaluation and research. Created in 2002, the Global Fund has committed US\$3.1 billion to more than 250 two year programmes in nearly 130 countries. It plans to disburse nearly US\$1 billion to over 200 programmes by the end of $2004 .^{40}$

In view of the growing influence of these new agencies, new ways to secure a high level of public accountability are required. This demand also applies to other institutions which issue national or international regulation relevant to pharmaceuticals - for example, drug regulatory authorities or the World Trade Organization.

The level, process, and outcome of the allocation of resources for health research, and in particular for rare or tropical diseases, can be expected to provide new ethical challenges in the global health policy arena.

\section{ACKNOWLEDGEMENT}

We would like to thank Professor Solomon Benatar, University of Cape Town, South Africa for his helpful comments to an earlier draft of this paper.

\section{Authors' affiliations \\ C A Gericke, A Riesberg, R Busse, Berlin University of Technology, Berlin, Germany}

C A Gericke is Senior Research Fellow in Health Care Management at the Berlin University of Technology, Germany. A Riesberg is Research Fellow in the Department of Health Care Management, Berlin University of Technology, and at the European Observatory on Health Care Systems and Policies. R Busse is Professor of Health Care Management, Berlin University of Technology, and Associate Research Director of the European Observatory on Health Care Systems and Policies.

\section{REFERENCES}

1 Council for International Organizations of Medical Sciences. International Ethical Guidelines for Biomedical Research Involving Human Subjects. www.cioms.ch/frame_guidelines_nov_2002.htm (accessed 21 October 2003).

2 Commission on Macroeconomics and Health. Macroeconomics and Health Investing in Health for Economic Development. Geneva: World Health Organization, 2001

3 Médecins Sans Frontières. Fatal Imbalance. The Crisis in Research and Development for Drugs for Neglected Diseases. Geneva: Médecins Sans Frontières Access to Essential Medicines Campaign and the Drugs for Neglected Diseases Working Group, 2001.

4 Global Forum on Health Research. Monitoring financial flows for health research. Geneva: Global Forum for Health Research, 2001

5 National Library of Medicine. Medical Subject Headings. Bethesda: National Library of Medicine, 1991.

6 Orphanet. What is an orphan drug? www.orpha.net/consor/cgi-bin/ home_Info.php?PHPSESSID =c2c2ccf314be9c80bf3b40a695dabb36\&file = MoDf (accessed 15 September 2003).

7 Pabst JY. Médicaments orphelins: quelques aspects juridiques, éthiques et économiques. Rev Epidemiol Sante Publique 2001 ;49:387-96.

8 European Parliament and the Council of the European Union. Regulation (EC) No 141/2000 of the European Parliament and of the Council of 16 
December 1999 on orphan medicinal products. Official Journal of the European Communities 2000;L18:1-5.

9 European Parliament and the Council of the European Union. Commission Regulation (EC) No 847/2000 of 27 April 2000 laying down the provisions for implementation of the criteria for designation of a medicinal product as an orphan medicinal product and definitions of the concepts "similar medicinal product" and "clinical superiority". Official Journal of the European Communities 2000;L103:5-8.

10 European Commission. Communication from the Commission on Regulation (EC) No 141/2000 on orphan medicinal products. Official Journal of the European Union 2003;C178:2

11 Beauchamp TL, Childress JF. Principles of Biomedical Ethics. Oxford: Oxford University Press, 2001.

12 Gillon R. Medical ethics: four principles plus attention to scope. BM 1994:309:184-8.

13 Beauchamp TL, Childress JF. Justice. Principles of Biomedical Ethics. Oxford: Oxford University Press, 2001:225-82.

14 Sassi F, Archard L, Le Grand J. Equity and the economic evaluation of healthcare. Health Technol Assess 2001:5:1-138.

15 Beauchamp TL, Childress JF. Moral theories. Principles of Biomedical Ethics. Oxford: Oxford University Press, 2001:337-83.

16 Cookson R, Dolan P. Principles of justice in health care rationing. J Med Ethics 2000;26:323-9.

17 DiMasi JA, Hansen RW, Grabowski HG, et al. Cost of innovation in the pharmaceutical industry. J Health Econ 2001;10:107-42.

18 Global Alliance for TB Drug Development. The Economics of TB Drug Development. New York: Global Alliance for TB Drug Development, 2001.

19 Global Forum for Health Research. The 10/90 Report on Health Research 2001-2002. Geneva: Global Forum for Health Research, 2002.

20 Gericke CA, Kurowski C, Ranson MK, et al. Feasibility of Scaling-up Interventions: The Role of Intervention Design, Working Paper No.13, Disease Control Priorities Project. Bethesda, Fogarty International Center National Institutes of Health, 2003, www.fic.nih.gov/dcpp/wps/wp13.pdf (accessed 15 December 2003).

21 Daniels $\mathrm{N}$. Is there a right to health care and, if so, what does it encompass? In: Kuhse H, Singer P, eds. A Companion to Bioethics. Oxford: Blackwell, 1998:316-25.

22 Den Exter A, Hermans $\mathrm{H}$. The right to health care: a changing concept? In: Den Exter A, Hermans H, eds. The Right to Health Care in Several European Countries. The Hague: Kluwer Law International, 1999:1-10.

23 Richards FO, Miri E, Meredith S, et al. Onchocerciasis. Bull World Health Organ 1998;76(suppl 2):147-9.

24 Beauchamp TL, Childress JF. Beneficence. Principles of Biomedical Ethics. Oxford: Oxford University Press, 2001:165-224.
25 Landman WA, Henley LD. Equitable rationing of highly specialised health care services for children: a perspective from South Africa. J Med Ethics 1999;25:224-9.

26 Issel LM, Kahn D. The economic value of caring. Health Care Manage Rev 1998;23:43-53.

27 Rhodes R. Organ transplantation. In: Kuhse H, Singer P, eds. A Companion to Bioethics. Oxford: Blackwell, 1998:329-42.

28 Royal College of Physicians. About the College. www.rcplondon.ac.uk/ college/about_home.htm (accessed 26 August 2003).

29 Ad hoc Committee on Health Research. Investing in Health Research and Development. Geneva: World Health Organization, 1996.

30 Willis R. The Works of William Harvey. London: Sydenham Society, 1847:616.

31 Maeder T. Adopting orphan diseases. www.redherring.com/ insider/2001/0122/tech-mag-90-orphan012201.htm (accessed 6 May 2003)

32 Goodman B. The biotech boom: big money in orphans www.redherring.com/insider/2001/0727/480019848.html (accessed 6 May 2003)

33 Zelzer E, Olsen BR. The genetic basis for skeletal diseases. Nature 2003:423:343-8.

34 Federal Drug Agency. List of All Orphan Products Designations and Approvals. www.fda.gov/orphan/designat/alldes.rff/accessed 2 September 2003).

35 European Agency for the Evaluation of Medicinal Products (EMEA). Press Release. 35th Meeting of the Committee for Orphan Medicinal Products. www.emea.eu.int/pdfs/human/comp/117303en.pdf (accessed 2 September 2003)

36 Daniels N, Sabin J. Limits to health care: fair procedures, democratic deliberation and the legitimacy problem for insurers. Philos Public Affairs 1997;26:303-50

37 Benatar SR, Singer PA. A new look at international research ethics. BMJ 2000;321:824-6.

38 Gericke C. Directory of poverty and health research, Report for the Department of Health and Development. Geneva: World Health Organization, 2001, www.iphn.org/DirectorywebFINAL.doc (accessed 29 October 2003).

39 Global Forum on Health Research. Strategic Orientations 2003-2005. www.globalforumhealth.org (accessed 22 October 2003).

40 The Global Fund to Fight AIDS, Tuberculosis and Malaria. The Global Fund reports its first country results. Geneva: The Global fund to fight AIDS, Tuberculosis and Malasia, July 2004. www.theglobalfund.org/en/ media_center/press/pr_04071 1 b.asp (accessed 15 September 2004). 